\title{
Sudden-onset paraplegia in a 72-year-old male with a spinal dural arteriovenous fistula: illustrative case
}

\author{
Ikenna I. Ogbu, MBBS, ${ }^{1}$ Nikolaos Tzerakis, MBBS, FRCS(SN), ${ }^{1}$ and Zaineb Al-Shamary ${ }^{2}$ \\ ${ }^{1}$ Department of Neurosurgery, Royal Stoke Hospital, University of North Midlands NHS Trust, Staffordshire, United Kingdom; and ${ }^{2}$ School of Medicine, Keele University, \\ Staffordshire, United Kingdom
}

\begin{abstract}
BACKGROUND Spinal dural arteriovenous fistulas (SDAVFs) are rare vascular malformations of the spine but account for up to $80 \%$ of all vascular malformations involving the spine. Few case reports of SDAVFs have been reported in the literature, and even fewer have been described with sudden onset of symptoms.

OBSERVATIONS The authors described the case of a 72-year-old male with sudden-onset bilateral paraplegia and sensory loss with subsequent inability to bear weight and an initial suspicion of cauda equina syndrome, which was eventually diagnosed as an SDAVF using magnetic resonance imaging. During open surgery, it was difficult to identify the feeder vessels. A postoperative scan showed persistence of the fistula, and the patient had to receive redo ligation with good postoperative status.
\end{abstract}

LESSONS Sudden-onset paraplegia is not the typical presentation of SDAVF. All doctors need to be aware of the possibility of an acute presentation with SDAVF, especially with the high likelihood of misdiagnosis and resultant worse outcome due to treatment delays. A high index of suspicion is required to ensure early recognition as well as initiation of treatment.

https://thejns.org/doi/abs/10.3171/CASE21283

KEYWORDS spinal dural arteriovenous fistula; spinal dAVF; spinal arteriovenous malformations

Despite being the most common vascular malformations encountered in the spine (approximately $80 \%$ of all spinal vascular neurological pathology), spinal dural arteriovenous fistulas (SDAVFs) are rare, accounting for only $1 \%$ to $2 \%$ of vascular neurological pathology. One of the main pitfalls of their rarity is that they are commonly underdiagnosed. ${ }^{1,2}$ Few case reports have described acute presentations with SDAVF. This case report describes an SDAVF in a 72-year-old man who presented acutely with bilateral paraplegia, sensory deficits, and urinary retention.

\section{Illustrative Case}

A 72-year-old male presented with a sudden onset of bilateral weakness that resulted in an inability to ambulate after a shower. His medical history includes well-controlled chronic low back pain, raised body mass index, benign prostatic hyperplasia, atrial fibrillation treated with apixaban, hypertension, hypercholesterolemia, glaucoma, and tuberculosis as a child. There was no history of weakness before the episode.

On examination at presentation, power was 1-2 in both lower limbs (LLs), progressing rapidly to 0/5 from initial assessment. Sensory level was at L1 with altered saddle and perianal sensation, with American Spinal Cord Injury Association (ASIA) total sensory score of 32 on the right side and 31 on the left side. The patient was hyporeflexic bilaterally and had urinary retention, with a residual volume of $1,000 \mathrm{~mL}$, which corresponds to grade 5 functional disability and grade 3 micturition dysfunction on the Aminoff disability scale. ${ }^{3}$ First working diagnosis in the emergency department after review by the spinal team was possible cauda equina syndrome. Initial magnetic resonance imaging (MRI) showed a thoracic DAVF.

Unenhanced spine MRI showed thoracic cord edema up to the conus with associated mild cord expansion. Additional MR angiography

ABBREVIATIONS ASIA = American Spinal Cord Injury Association; ICG = indocyanine green; $L L=$ lower limb; $M R A=$ magnetic resonance angiograpy; $M R I=$ MR imaging; SDAVF = spinal dural arteriovenous fistula.

INCLUDE WHEN CITING Published August 30, 2021; DOI: 10.3171/CASE21283.

SUBMITTED May 22, 2021. ACCEPTED June 22, 2021.

(c) 2021 The authors, CC BY-NC-ND 4.0 (http://creativecommons.org/licenses/by-nc-nd/4.0/). 
(MRA) at the time showed a dural fistula at the T11 vertebral pedicle with mostly cranial venous drainage (Figs. 1 and 2).

During his initial operation, two vessels were identified as suspected feeder vessels using indocyanine green (ICG) to assess arterial filling; however, the medullary vein collapsed with the application of a temporary clip to the medial vessel, resulting in reduced venous filling and no further feeder filling with ICG. The decision was then made to leave the lateral vessel because it was unclear whether it was the artery of Adamkiewicz (arteria radicularis anterior magna).

In the immediate postoperative period, there was marked improvement in the patient's sensation, with ASIA chart scores from 30 and 32 to 31 and 33 on the left and right sides, respectively. The patient was moving both ankles after the first procedure (7 days postoperatively) while awaiting MRA. Knee flexion was $1 / 5$ on the right side and 0/5 on the left side.

Postoperative spinal angiography showed that the T11 intradural fistula remained without occlusion or interruption. The patient thus received reoperation, during which the previously dilated medullary vein was found to be normal in diameter and the second feeder (as previously identified during the first operation) was isolated, coagulated, and divided.

On postoperative day 1 after his second operation, the patient was found to already have improved power in both LLs, with improved knee flexion bilaterally; this progressively improved at postoperative day 5 to $2+/ 5$ bilaterally (slightly better in the right $\mathrm{LL})$, with the physiotherapists also noting significant improvement. This power progressively improved with continuing physiotherapy, with significant antigravity movement $(4 / 5)$ noted by postoperative day 19, and he was ambulating independently with a Zimmer frame at the time. Repeat MRA was also performed after a neurovascular multi-disciplinary team meeting, which determined that the dural arteriovenous fistula was successfully treated on postoperative day 21 (Fig. 3).

\section{Discussion}

SDAVFs are the most common vascular abnormality in the spinal cord; however, they are rare, accounting for only approximately $2 \%$ of

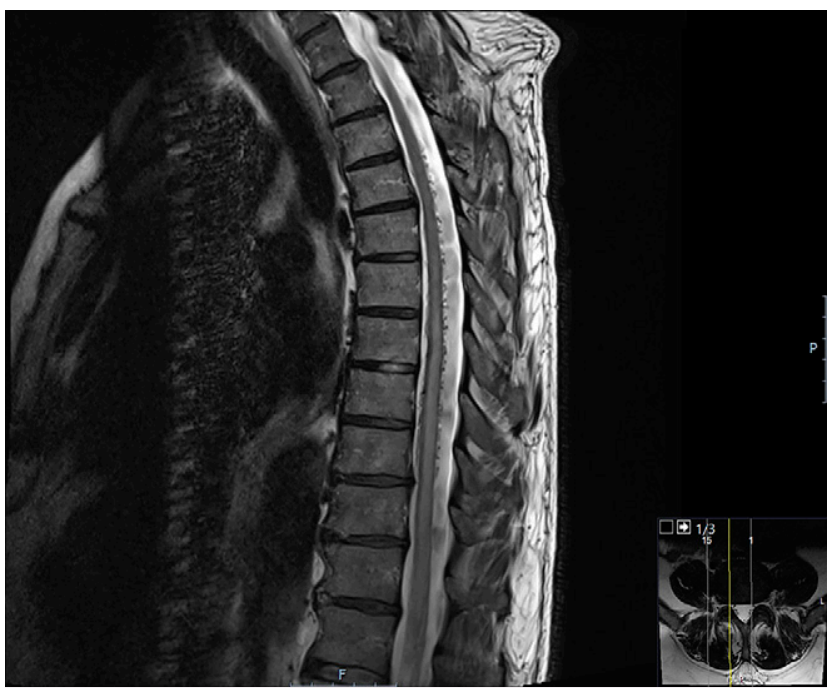

FIG. 1. Preoperative $T 2$ sequence showing perimedullary flow voids indicative of SDAVF. Inset: Axial slice showing the plane at which the larger image was taken.

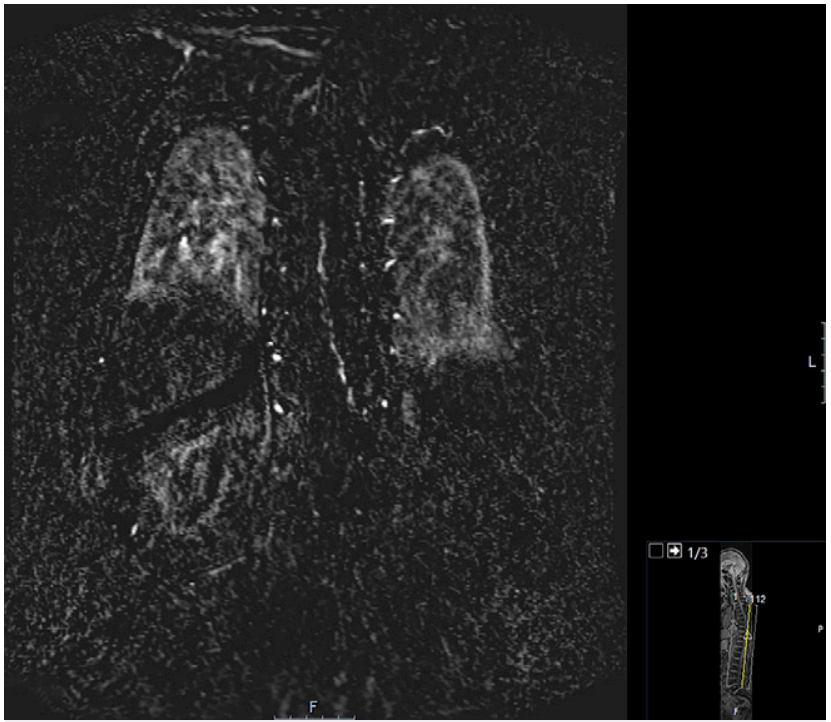

FIG. 2. Preoperative MRA showing the feeder vessels and medullary vein of the SDAVF. Inset: Sagittal slice showing the plane at which the larger image was taken.

all vascular neurological pathologies, and are typically prognosticated by the extent of neurological deficit at presentation. ${ }^{4,5}$ Thus, early identification is crucial to improving outcomes. SDAVF is sometimes called Foix-Alajouanine syndrome when it is associated with myelopathy. ${ }^{4}$ SDAVF can be classified as extradural or intradural, which is elaborated in the Speltzer classification in Table 1.

Most patients presenting with SDAVFs are usually males in their early 60 s, and time to presentation, as has been typically reported in the literature, is at least 4 weeks. ${ }^{1}$ Most SDAVFs occur at the thoracic level, with approximately $19 \%$ of patients in a case series having a fistula at the T7 level. ${ }^{5}$ With SDAVF, there is also a phenomenon referred to as corticosteroid-induced paraplegia, which is sometimes used as a diagnostic clue. ${ }^{6,7}$

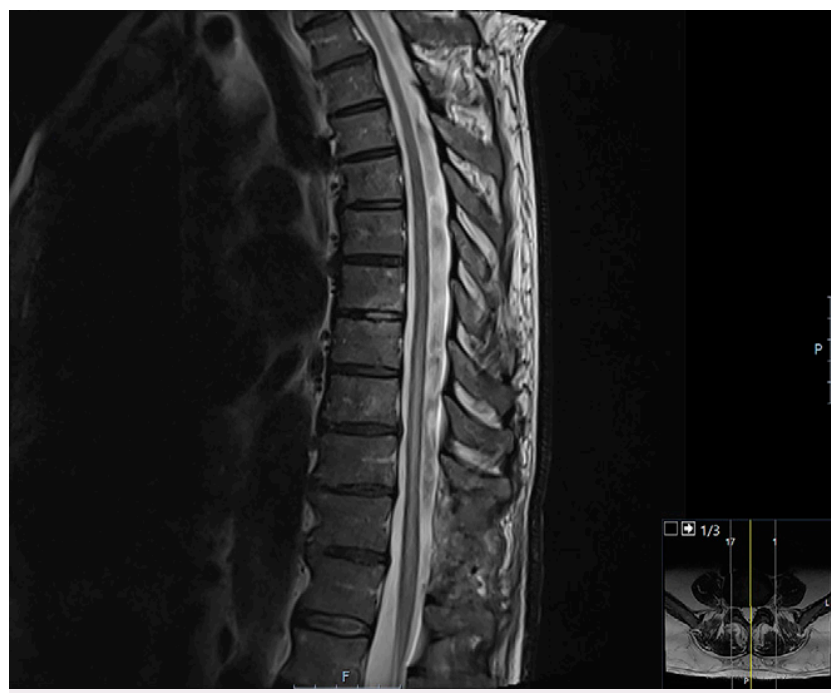

FIG. 3. Postoperative MRI T2 sequence showing improved cord signal and no evidence of a residual fistula. Inset: Axial slice showing the plane at which the larger image was taken. 
TABLE 1. Spetzler's classification of spinal vascular lesions

\begin{tabular}{|c|c|c|}
\hline $\begin{array}{c}\text { Neoplastic Vascular } \\
\text { Lesion }\end{array}$ & $\begin{array}{c}\text { Hemangioblastoma } \\
\text { Cavernous Malformation }\end{array}$ & \\
\hline \multicolumn{3}{|l|}{ Spinal aneurysms } \\
\hline \multirow[t]{5}{*}{$\begin{array}{l}\text { Arteriovenous } \\
\text { malformation }\end{array}$} & $\begin{array}{l}\text { Extradural- } \\
\text { intradural }\end{array}$ & \\
\hline & Intradural & Intramedullary \\
\hline & & Compact \\
\hline & & Diffuse \\
\hline & & Conus medullaris \\
\hline \multirow{3}{*}{$\begin{array}{l}\text { Arteriovenous } \\
\text { fistulae }\end{array}$} & Extradural $^{*}$ & \\
\hline & Intradural $^{\dagger}$ & $\begin{array}{c}\text { Dorsal }^{\dagger} \\
1=\text { single feeder } \\
2=\text { multiple feeders }\end{array}$ \\
\hline & & $\begin{array}{c}\text { Ventral } \\
1=\text { small shunt } \\
2=\text { medium shunt } \\
3=\text { large shunt }\end{array}$ \\
\hline
\end{tabular}

\footnotetext{
* Can be treated more effectively by endovascular methods.

${ }^{\dagger}$ Most common type of spinal AVF, occurring in the thoracic region.

Includes data from Spetzler et al. ${ }^{10}$
}

SDAVF only presents acutely in about $5 \%$ of cases; however, the exact nature of this acute presentation was not described by Fugate et al. ${ }^{8}$ Difficulty in diagnosing SDAVF has been highlighted by various articles; it is rare, with initial symptoms being nonspecific in most cases. Differential diagnoses at presentation range from lumbar canal stenosis to Guillain-Barre syndrome and amyotrophic lateral sclerosis to diabetic neuropathy. ${ }^{1}$ This range can result in a diagnostic delay of 18 months on average and up to 197 months. ${ }^{5,8}$ Symptoms typically worsen with Valsalva-type activities (or any activities resulting in increased venous pressure) and improve with rest. ${ }^{8}$ Up to $80 \%$ of patients present with micturition problems at the time of diagnosis, with $78 \%$ and $69 \%$ of patients also presenting with motor and sensory problems, respectively, ${ }^{5}$ and up to $20 \%$ of patients presenting with pain involving the back and/or legs, ${ }^{9}$ as was seen in our index patient. Up to $16 \%$ of patients also present with unilateral symptoms. ${ }^{8}$ Symptoms at presentation are usually graded using the Aminoff and Logue scale of disability, which ranks severity based on micturition and motor symptoms. ${ }^{3}$

The main pathophysiology of SDAVFs, especially the intradural variety, is venous hypertension-induced myelopathy, which is commonly misdiagnosed as lumbar stenosis. ${ }^{10}$ This condition is indicated radiologically by stasis, edema, and ischemia.

The main findings on MRI that suggest the possibility of an SDAVF include cord swelling, demonstrated by increased T2 signaling within the cord, and parenchymal enhancement, both of which are nonspecific. The most specific MRI finding is enlarged vessels on the surface of the cord, which is only found in approximately $50 \%$ of patients with SDAVF. ${ }^{11}$ In most cases, T2 hypointensity of the cord periphery is seen, which is suggestive of a venous hypertensive myelopathy, especially in the absence of hemorrhage. Multisegment hyperintensities with associated subarachnoid flow voids are pathognomonic of SDAVF.111 However, definitive diagnosis and localization are only achieved using spinal angiography. ${ }^{1}$
The mainstay of treatment for SDAVFs is usually embolization or open surgery, based on their classification (Table 1). For extradural AVFs, embolization is typically the preferred option, whereas the approach to intradural AVFs is either embolization or open surgery, with open surgery preferred because of reduced recurrence, reduced morbidity, and improved success rates compared with embolization, with only $25 \%$ of patients who received embolization achieving results similar to open surgery and up to $75 \%$ reoperation rates after failed embolization. ${ }^{3,10}$

Typically, the anterior spinal artery does not arise at the same level as the SDAVF. However, in the event that it does, an endovascular approach is then contraindicated, and surgical treatment would be the preferred approach. ${ }^{12}$

\section{Observations}

Our index patient presented acutely with a history of suddenonset bilateral weakness and inability to bear weight, which is an unusual presentation according to documented case reports and case series, with the shortest interval between clinical symptom onset and diagnosis having been reported as 7 days ${ }^{5}$ and only $10 \%$ of patients having $<1$ month between symptom onset and diagnostic confirmation. ${ }^{3}$ Most patients typically recover after interruption of the fistula, which is typically more marked within the first 3 months after surgery/endovascular treatment. ${ }^{13}$ Considering the early presentation of this patient and the correlation between time to diagnosis and outcomes, it is not surprising that the patient achieved substantial recovery after surgical intervention. This highlights the need for a high index of suspicion, early diagnosis, and early intervention to obliterate the fistulous connection.

\section{Lessons}

All doctors need to be aware of the possibility of acute presentation of an SDAVF because misdiagnosis and subsequent delay in diagnosis are common and can lead to worse outcomes. An awareness of this condition, an understanding of the pathophysiology and the spectrum of presentation of SDAVFs, and a high index of clinical suspicion are required for early diagnosis and initiation of adequate treatment.

\section{Acknowledgments}

We would like to thank the patient who provided consent for publication and was supportive and responsive to our requests during the writing of this case report. We would also like to acknowledge Mr. Stuart Harrisson, Consultant Trauma and Spine Neurosurgeon at the University Hospitals of North Midlands (UHNM), for his substantive contribution toward the production of this illustrative case, clinically during the patient's management and with supportive guidance during the writing of this report, without which we would not have been able to publish this article.

\section{References}

1. Fox S, Hnenny L, Ahmed U, Meguro K, Kelly ME. Spinal dural arteriovenous fistula: a case series and review of imaging findings. Spinal Cord Ser Cases. 2017;3(1):17024.

2. Krings T, Geibprasert S. Spinal dural arteriovenous fistulas. AJNR Am J Neuroradiol. 2009;30(4):639-648.

3. Van Dijk JMC, TerBrugge KG, Willinsky RA, Farb RI, Wallace MC. Multidisciplinary management of spinal dural arteriovenous fistulas: clinical presentation and long-term follow-up in 49 patients. Stroke. 2002;33(6):1578-1583. 
4. Krishnan P, Banerjee TK, Saha M. Congestive myelopathy (FoixAlajouanine syndrome) due to intradural arteriovenous fistula of the filum terminale fed by anterior spinal artery: case report and review of literature. Ann Indian Acad Neurol. 2013;16(3):432-436.

5. Jellema K, Canta LR, Tijssen CC, van Rooij WJ, Koudstaal PJ, van Gijn J. Spinal dural arteriovenous fistulas: clinical features in 80 patients. J Neurol Neurosurg Psychiatry. 2003;74(10):1438-1440.

6. DiSano MA, Cerejo R, Mays M. Acute paraparesis and sensory loss following intravenous corticosteroid administration in a case of longitudinally extensive transverse myelitis caused by spinal dural arteriovenous fistula: case report and review of literature. Spinal Cord Ser Cases. 2017;3(1):17025.

7. O'Keeffe DT, Mikhail MA, Lanzino G, Kallmes DF, Weinshenker BG. Corticosteroid-induced paraplegia-a diagnostic clue for spinal dural arterial venous fistula. JAMA Neurol. 2015;72(7):833-834.

8. Fugate JE, Lanzino G, Rabinstein AA. Clinical presentation and prognostic factors of spinal dural arteriovenous fistulas: an overview. Neurosurg Focus. 2012;32(5):E17.

9. Muralidharan R, Saladino A, Lanzino G, Atkinson JL, Rabinstein AA. The clinical and radiological presentation of spinal dural arteriovenous fistula. Spine (Phila Pa 1976). 2011;36(25):E1641-E1647.

10. Spetzler RF, Detwiler PW, Riina HA, Porter RW. Modified classification of spinal cord vascular lesions. J Neurosurg. 2002;96(2 suppl): 145-156.

11. Hurst RW, Grossman RI. Peripheral spinal cord hypointensity on T2-weighted MR images: a reliable imaging sign of venous hypertensive myelopathy. AJNR Am J Neuroradiol. 2000;21(4):781-786.
12. Ances BM. Neuroradiology: The Requisites. 2nd ed. Neurology. 2005;64(2):E16.

13. Ma Y, Chen S, Peng C, et al. Clinical outcomes and prognostic factors in patients with spinal dural arteriovenous fistulas: a prospective cohort study in two Chinese centres. BMJ Open. 2018;8(1):e019800.

\section{Disclosures}

The authors report no conflict of interest concerning the materials or methods used in this study or the findings specified in this paper.

\section{Author Contributions}

Conception and design: Ogbu. Acquisition of data: Ogbu. Analysis and interpretation of data: Ogbu. Drafting the article: Ogbu, Al-Shamary. Critically revising the article: Ogbu, Tzerakis. Reviewed submitted version of manuscript: Ogbu, Tzerakis. Approved the final version of the manuscript on behalf of all authors: Ogbu. Administrative/technical/ material support: Ogbu, Tzerakis. Study supervision: Tzerakis.

\section{Correspondence}

Ikenna I. Ogbu: Royal Stoke Hospital, University of North Midlands NHS Trust, Staffordshire, United Kingdom. ikenna.ogbu@uhnm.nhs.uk; ogbuikenna@yahoo.co.uk. 